\title{
EFFECT OF SALINITY ON THE OXYGEN CONSUMPTION OF TILAPIA FINGERLINGS
}

\author{
Md. Abdul Awal, Kartik Chandra Kuri and Subrata Sarker \\ Institute of Marine Sciences and Fisheries, University of Chittagong, Bangladesh \\ E-mail: subratasrkr59@gmail.com
}

\begin{abstract}
Fingerlings of tilapia were used to compare the oxygen consumption rates at 0,10,20 and $30 \mathrm{ppt}$ salinity. Oxygen consumption of tilapia at 0, 10, 20 and 30 ppt salinity was found 2.14, 0.71, 1.43 and $1.42 \mathrm{ml} /$ liter/h respectively. Oxygen consumption rate thereafter decreased with increasing salinity, although the lowest consumption occurred at 10 ppt. Lower consumption at high salinities might be a result of reduced activity, which in itself was salinitymodulated. The fish in this study were in or near a resting state, and that differences in oxygen consumption rates probably were related to the energetic cost of ionic and osmotic regulation. Again, mechanism in the fill tissue might involve significant energy-consuming processes in different water salinities compared to fresh water.
\end{abstract}

Keywords: Fingerlings, water salinities, Ionic regulation and osmic regulations

\section{Introduction}

Tilapia known as aquatic chicken (Macllean, $\mathrm{JL}, 1984$ ) is one of the world's commercially important euryhaline species suitable for intensive maricutlture. Tilapia is readily available with relatively low production cost. Tilapia is also common and popularly accepted by people and can be sold in wet market a din restaurants featuring live sea food cuisine.

Tilapia is characterized by a general tolerance to wide range of environmental conditions. This tolerance is not limited to saline waters but also includes environments with poor water quality. Among Other factors, good growth and prolific breeding have certainly favored the large tilapia culture observed in recent years. Competition with agriculture has increased pressure to develop tilapia aquaculture in marginal areas such as brackish water or sea water (Payne, 1983). But the metabolic cost Date of submission : 24. 04. $2010 \quad$ Date of acceptance : 06. 03. 2011 for osmoregulation is not well understood in these fishes. Oxygen consumption has been used as an indirect indicator of metabolism of fish (Cech, 1990) and the energenitic cost of ionic and osmotic regulations seems to play a significant role tin growth rates (Boeuf and Payan, 2001). Therefore, it is important to know the oxygen consumption of tilapia in different salinities and the present trial was to examine the energy requirements of osmoregulation indirectly in fingerlings of tilapia.

\section{Materials and Methods}

Fish Collection: Fishes are collected $(6 \pm 0.3 \mathrm{~g} ; 5.5 \pm 0.3 \mathrm{~cm})$ by net casting from the different pond. They were brought to lab where they were held in freshwater tanks.

\section{Laboratory setup}

One day prior to experiment, the following acclimation procedure were carried out in fore cylindrical glass jars (5 liter), designated for fresh water $(0 \%)$, saline water $(10 \%)$, saline water (20\%o) and saline water (30\%o).

\section{Salinity adjustment}

The saline water obtained from reserved brine water (150\%). Salinity levels were obtained by mixing pond water to brine water and adjusted using an optical refractrometer to the nearest $1 \mathrm{ppt}$.

\section{Aeration}

The four jars initially received a continuous aeration for 12 hours. The temperature range over the course of the experiment was $31^{\circ} \mathrm{C}$ to $33^{\circ} \mathrm{C}$ and did not differ among the jars. 


\section{Experiment}

After acclimation (6 hours) three fish of both sexes were placed in each of the jar. The duration of the experiments was 2 hours. The initial Dissolve Oxygen (DO) of each jar was determined before placing the fishes into the jar. After two hours the final DO was determined.

\section{Oxygen Consumption Measurement}

The oxygen consumption was determined by Winkler's titration method (Strickland and Parsons, 1972). The oxygen consumption was expressed as: (Initial DO-Final DO)/T $\mathrm{ml} /$ liter/h.

Where, $\mathrm{T}=$ time.

\section{Results}

Oxygen consumption of tilapia at $0,10,20$ and 30 ppt salinity was found $2.14,0.71$, 1.43 and $1.42 \mathrm{ml} / \mathrm{liter} / \mathrm{h}$ respectively. Oxygen consumption rates thereafter decreased with increasing salinity, although the lowest consumption occurred at $10 \mathrm{ppt}$.

\section{Discussion}

Oxygen consumption decreased with increasing salinity. Lowest oxygen consumption was recorded in salinity of 10 ppt. Farmer and Beamish (1969) have been reported low consumption in Tilapia nilotica at higher salinities of up to $30 \mathrm{ppt}$, although the lowest consumption occurred at $11.2 \mathrm{ppt}$, which is coincided with the present study. These observations provide an indirect support for relationship between oxygen consumption and osmotic regulation.

In the present study it has been seen that oxygen consumption in different salinities was almost half of the consumption in fresh water. Ron et al. (1995) also showed that fish in sea water had significantly lower oxygen consumption rate (half) compared to fish reared in fresh water.
Furthermore, Ron et al. (1995) speculated that the difference in the possible energetic cost of ionic and osmotic regulation played a significant role in the difference in growth rate between the two groups; the sea water fish grew to be 1.5 times larger than the fish in fresh water. They reasoned that the change in oxygen consumption rate that could be attributed to the decrease in metabolic rate related to the increasing body size should be in the order to about $10 \%$, far lower than the observed 50\% between fresh and sea water (Ron et al., 1995).

Swanson (1996) also observed that the oxygen consumption paradoxically decreased at salinities far above that of the seawater in the milkfish (Chanos chanos). It was suggested that the low oxygen consumption at high salinities was rather a result of the reduced activity, which in itself was salinity-modulated. This probably explains the results of his study since fish at higher salinity were visibly less active than those at fresh water.

Such difference in oxygen consumption rates among salinities raises the question of what process and mechanisms were involved. The level of feeding and feeding activity, as well as the increased metabolic rate following feeding all influence overall metabolic rate, and thus oxygen consumption; although it is not applicable in this study. The fish in this study were in or near a resting state, and that differences in oxygen consumption rates probably were related to the energetic cost of ionic and osmotic regulation. Again, mechanisms in the gill tissue might involve significant energy-consuming processes in different water salinities.

\section{Conclusions}

It was observed in the present study that oxygen consumption was decreased which indicated lower metabolic cost. As the metabolic cost was decreased, surplus energy might be used for enhancement of growth of the species in saline water. 


\section{References}

[1] Boeuf, G. and Payan, P. 2001. How should salinity influence fish growth? Compound Biochemistry physiology, 130, 411-423.

[2] Cech, J.J. 1990. Respirometry. In Methods for fish biology, editor. C.B. Schreck and P. B. Moyle. American Fisheries Society, Bethesda, Maryland.

[3] Farmer, C.J. and F.W.H. Beamish. 1969. Oxygen consumption in Tilapia nilotica in relation with swimming speed and salinity. Journal of the Fisheries Research Board of Canada 26: 07-28.

[4] Febry, R. and Lutz, P. 1987. Energy partitioning in fish: the activity-related cost of osmoregulation in euryhaline cichlid. Journal of Experimental Biology 128: 63-85.
[5] Iwama, G. K., Takemure, A. and Takano, K. 1997. Oxygen consumption rates of tilapia in fresh water, sea water and hyper saline sea water. Journal of Fish Biology 51: 886-894.

[6] Maclean, JL. 1984. Tilapia the aquatic chicken. ICLARM Newsletter, 7(1):3-17.

[7] Payne A. I. 1984. Estuarine and Salt tolerant tilapias. I: Proc. International Symposium. Tilapia in aquaculture. Tel Aviv University. 534543.

[8] Ron et al. 1995. Tilapia, biology and nutrition. 91 $p$.

[9] Swamspm, C. 1996. Early development of milk fish: Effects of salinity on embryonic and larval metabolism, yolk absorption and growth. Journal of Fish Biology 48: 405-421. 